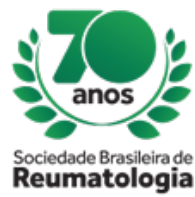

\title{
SHRINKING LUNG SYNDROME - RARE AND SEVERE CLINICAL CONDITION ASSOCIATED WITH SYSTEMIC
} LUPUS ERYTHEMATOSUS

Frederico Palumbo Araujo (Hospital das Clínicas Samuel Libânio, Pouso Alegre, MG, Brasil), lane Bacil Abreu Barbosa Leal (Hospital das Clínicas Samuel Libânio, Pouso Alegre, MG, Brasil), Maicon Felipe Ribeiro da Cruz (Hospital das Clínicas Samuel Libânio, Pouso Alegre, MG, Brasil), Renato de Rezende Gama Veiga (Hospital das Clínicas Samuel Libânio, Pouso Alegre, MG, Brasil), Luis Claudio Elias Azevedo (Hospital das Clínicas Samuel Libânio, Pouso Alegre, MG, Brasil), Nathalia de Souza Romanelli (Hospital das Clínicas Samuel Libânio, Pouso Alegre, MG, Brasil), Hudson Umeoka Junior (Hospital das Clínicas Samuel Libânio, Pouso Alegre, MG, Brasil), Thiago Noia de Alcantara e Oliveira (Hospital das Clínicas Samuel Libânio, Pouso Alegre, MG, Brasil), Carolina Lessa Rezende Santos (Hospital das Clínicas Samuel Libânio, Pouso Alegre, MG, Brasil), Eduardo Junqueira Cruz (Hospital das Clínicas Samuel Libânio, Pouso Alegre, MG, Brasil), Joao Marcos de Oliveira Junior (Hospital das Clínicas Samuel Libânio, Pouso Alegre, MG, Brasil), Paula Natasha Ribeiro de Faria (Hospital das Clínicas Samuel Libânio, Pouso Alegre, MG, Brasil), Jorge Luis de Carvalho Melo (Hospital das Clínicas Samuel Libânio, Pouso Alegre, MG, Brasil), Maria Esther de Rezende Correa (Hospital das Clínicas Samuel Libânio, Pouso Alegre, MG, Brasil), Lilia Freitas Oliveira (Hospital das Clínica Samuel Libânio, Pouso Alegre, MG, Brasil), Ricardo Lehnen Michelete (Hospital das Clínica Samuel Libânio, Pouso Alegre, MG, Brasil), lasmym Faccio (Hospital das Clínica Samuel Libânio, Pouso Alegre, MG, Brasil), Aline Silva Rezende (Hospital das Clínica Samuel Libânio, Pouso Alegre, MG, Brasil), José Renato de Melo (Hospital das Clínica Samuel Libânio, Pouso Alegre, MG, Brasil), Sebastião Jupiaçara Guimarães (Hospital das Clínica Samuel Libânio, Pouso Alegre, MG, Brasil)

\section{BACKGROUND}

Systemic lupus erythematosus (SLE) is characterized by a systemic autoimmune condition that can involve the respiratory system in several ways: pleuritis, pneumonitis, interstitial disease or pulmonary hypertension. Rarely, it may present a syndrome characterized by dyspnea, chest pain, spirometrics alterations and absence of significant parenchymal alterations in chest tomographic (CT): known as shrinking lung syndrome (SLS).

\section{CASE REPORT}

A.C.R, 29 years-old, a female patient, sought medical attention with reports of chronic inflammatory polyarthralgia in small joints, associated with fever, severe dyspnea and ventilatory-dependent chest pain beginning a week ago. She denied skin lesions, photosensitivity, mucosal ulcers, Raynaud and neurological changes.

On physical examination, the patient was in anasarca, tachycardic, tachypneic, with intercostal retractions and low oxygen saturation in ambient air. Pulmonary auscultation evidenced reduction of vesicular murmur in the right pulmonary base.

Chest X-ray showed elevated right hemidiaphragm without significant parenchymal changes. This finding was confirmed by CT angiography of the chest, that excluded the diagnosis of pulmonary thromboembolism. Arterial gasometry showed hypoxemia and spirometry restrictive disorder.

Laboratory tests: Homogeneous Nuclear FAN 1:640. Anti-native DNA 1:160. Anti-SM 480. Anti-RNP 139. Anti-Ro and Anti-La negatives. Proteinuria: $694 \mathrm{mg} / 24$ hours. C3 and C4 consumed. Leukopenia and anemia of chronic disease. Negative Serologies for Syphilis, Hepatitis B and C and HIV.

Due to the respiratory insufficiency, intensive care was required, with pulse therapy with methylprednisolone and cyclophosphamide, in addition to physiotherapeutic support, noninvasive 
ventilation and oxygen supply for a long period. High doses of prednisone, monthly infusions of cyclophosphamide and hydroxychloroquine were maintained. Patient was discharged in good conditions after one month of hospital admission.

\section{CONCLUSION}

SLS is characterized by the appearance of dyspnea and ventilator-dependent chest pain. There is a disproportion between the changes seen in pulmonary function tests (which show severe restrictive ventilatory disorder) and the radiological findings, where only the diaphragmatic dome elevation is evidenced uni or bilaterally and absence of parenchymal involvement.

There are hypotheses that there is dysfunction of the diaphragmatic muscle secondary to phrenic nerve damage, diffuse fibrosis of the diaphragm or restriction of the expandability of the thoracic wall.

Treatment of SLS is also not defined. In cases described in the literature, corticosteroids, immunosuppressants and inhaled beta-agonist (because of its positive inotropic effect of on the diaphragmatic muscle) were used. Xanthines and even digitalis may be used with the argument that the diaphragm would respond to this drug similarly to the heart muscle. 